\title{
Mental disorders in primary health care: a study of their frequency and diagnosis in four developing countries
}

\author{
T. W. HARDING, ${ }^{1}$ M. V. DE ARANGO, ${ }^{2}$ J. BALTAZAR, ${ }^{3}$ \\ C. E. CLIMENT, ${ }^{2}$ H. H. A. IBRAHIM, ${ }^{4}$ L. LADRIDO-IGNACIO, \\ R. SRINIVASA MURTHY' AND N. N. WIG ${ }^{6}$ \\ Investigators in a WHO Collaborative Study on Strategies for \\ Extending Mental Health Care
}

\begin{abstract}
SYNOPSIS 1624 patients who were attending primary health facilities in 4 developing countries were examined to determine how many were suffering from mental disorder. Using stringent criteria to establish the presence of psychiatric morbidity, 225 cases were found, indicating an overall frequency of $13.9 \%$. The great majority of cases were suffering from neurotic illnesses and for most the presenting complaint was of a physical symptom, such as headache, abdominal pain, cough or weakness. The health workers following their normal procedure correctly detected one third of the psychiatric cases.
\end{abstract}

\section{INTRODUCTION}

How frequent are mental disorders among patients presenting at the primary level of health care? Advances in techniques of reliable case detection (Goldberg, 1974) have led to a number of studies which have shown that nonpsychotic psychiatric illness is one of the most common reasons for which doctors are consulted. Goldberg \& Blackwell (1970), in one of the first studies to be based on more efficient research instruments than had been previously available, found the 'conspicuous psychiatric morbidity' of a London, UK, general practice

\footnotetext{
1 Address for correspondence: Dr T. W. Harding, Medical Officer, World Health Organization, 1211 Geneva 27, Switzerland. Principal investigator for the study.

Department of Psychiatry, Universidad del Valle, Cali, Colombia. Co-investigator and chief investigator respectively of study area team in Colombia.

- Institute of Public Health, Manila, Philippines. Coinvestigator of study area team in Philippines.

- Department of Psychiatry, Faculty of Medicine, University of Khartoum, Khartoum, Sudan. Chief investigator of study area team in Sudan.

- Department of Psychiatry, University of the Philippines System, Manila, Philıppines. Chief investigator of study area team in Philippines.

- Department of Psychiatry, Postgraduate Institute of Medical Education and Research, Chandigarh, India. Coinvestigator and chief investigator respectively of study area team in India.
}

to be $20 \%$. Similar findings have been reported from other industrialized countries (Giel \& Le Nobel, 1971).

It would obviously be a mistake to assume that the same result would be found in developing countries. There, primary health care is very different, relying much more on simply trained community health workers, and the incidence and prevalence of conditions such as malnutrition and infections are much higher. It would therefore be reasonable to assume that, under such conditions, fewer patients with mental disorder might come to primary health care facilities and that those who do would be numerically overshadowed by common, physical disorders such as malaria, tuberculosis, gastro-enteritis and pneumonia. Nevertheless, a few studies have suggested that the rate of mental disorders seen in primary health care may in fact be of the same order in the developing countries as elsewhere (Giel \& Van Luijk, 1969; Mbanefo, 1971; Harding, 1973; Ndetei \& Muhangi, 1979). Some further support is given to these observations by studies of mental disorders at the second level of health care (Holmes \& Speight, 1975; McEvoy \& McEvoy, 1976). However, these are all rather scattered, small-scale studies which, for a number of reasons, may be unrepresentative. 
This paper describes a study in which consecutive, adult patients ${ }^{1}$ attending primary health facilities in defined areas of 4 developing countries were screened for the presence of mental disorder. The diagnostic behaviour of the existing health workers is also described.

The study was undertaken as part of the baseline observations in the WHO Collaborative Study on Strategies for Extending Mental Health Care (Harding, 1978; WHO, 1979). The study's aim is to develop and evaluate low cost methods of mental health care as an integral part of general health services. After the baseline observations were completed, the health workers in each of the study areas participating in the study $^{2}$ have received brief, task-oriented training on the detection and management of a limited number of priority mental disorders. A number of the planned interventions will involve community agents such as teachers, policemen, communal leaders or village chiefs and, in some cases, traditional healers. Nevertheless, the primary health care facilities will be an important focus of action and it was therefore essential to know, prior to the interventions, the answers to the following. How many and what type of mental disorders are already present among patients coming for primary health care? What proportion is correctly identified by the health workers? Which presenting complaints are commonly associated with the presence of a psychiatric disturbance? This paper gives the answers to these questions from 4 developing countries.

\section{METHOD}

\section{The study areas}

The screening exercise (for which results are reported in this paper) was carried out in 4

\footnotetext{
1 A similar study has been carried out in the same areas with children. The results are being published separately (Giel et al. in preparation). A survey of community attitudes and perceptions has also been carried out (Wig et al. 1980).

" 'First-phase' study areas are: Union de Vivienda Popular in Cali, Colombia; Raipur Rani, Haryana State, India; Niakhar, Region of Sine Saloum, Senegal; Shagara Jebel Awlia, Khartoum Province, Sudan. In 1977/8 further teams have started work in Brazil, Egypt and the Philippines. Results from the team working in Sampaloc, Manila, in the Philippines, are already available and are reported here. In the Niakhar study area a modified method for case identification has been used with a one-stage screening of a much larger number of individuals. The Niakhar results will therefore be reported separately.
}

defined study areas: (i) Union de Vivienda Popular (UVP), a crowded, poor barrio on the outskirts of the city of Cali, Colombia, with a population of 63757 (1974); (ii) Raipur Rani (RR), a rural area in the state of Haryana, India, with a population of 64642 (1976); (iii) Shagara Jebel Awlia (SJA), an agricultural zone in Khartoum Province, Sudan, with a population of 58655 (1975); (iv) Sampaloc (SAM), a densely populated area in Manila, Philippines, with a population of 75388 (1975).

\section{Sampling}

In each area a complete list of all health facilities was drawn up, together with information on the average number of consultations by adults each week in each facility. The minimum number of adults to be screened was fixed as 300 per 50000 inhabitants. A screening quota was then established for each health facility in proportion to the attendance rates. (Thus, in an area with a population of 60000 with 4 health facilities with average daily attendance rates of $95,60,15$ and 10 respectively, a total screening target of 360 would be set with individual health facility quotas of 190, 120, 30 and 20 respectively.)

Screening was then carried out at each facility in turn. Consecutive attenders aged 16 or over were screened on successive days until the quota was reached. Screening always commenced with the first patient attending in the morning. Excluded from screening were: (i) patients who were so seriously ill (e.g. in coma) or required such urgent medical care that it would be unreasonable to administer the research questionnaires; (ii) patients who refused to take part; (iii) patients who had already attended once during the exercise and had therefore been screened.

\section{Reason for attendance and health staff rating}

For each patient screened, basic identifying data were obtained (age, sex, marital status and occupation) and the patient was asked why he or she had come to the health facility, the response being recorded verbatim. The screening process (see section 4) was carried out completely independently of the usual consultation/ treatment process, the results not being available to the health worker who was seeing the patient. This health worker indicated at the end of the normal consultation process whether or not he/ 
she thought mental disorder was present, by marking a cross against 1 of 5 items on a Health Staff Rating schedule (HSR). The items were:

(1) a physical health problem only,

(2) a mental health problem only,

(3) a physical and mental health problem,

(4) no health problem of any kind,

(5) no rating possible.

\section{First-stage screening}

A Self Reporting Questionnaire (SRQ) with 24 items was used. The first 20 items were designed to detect non-psychotic disorders. They were selected by a consensual process, comparing items in 4 instruments used in a variety of cultural settings: the Patient Self-report Symptom Form (PASSR), an instrument developed and tested in Cali, Colombia (Climent \& Plutchick, 1980); the PGI Health Questionnaire $\mathrm{N} 2$ developed by Wig and his colleagues in Chandigarh after they found the Cornell Medical Index to be inappropriate to the Indian setting (Verma \& Wig, 1977); the General Health Questionnaire (GHQ) used originally by Goldberg in England but subsequently validated in the United States (Goldberg, 1972), Jamaica (Harding, 1976), and many other settings; the 'symptom' items on the shortened version of the Present State Examination (PSE) (Wing et al. 1974). The full version of the PSE has been adapted and tested in a wide range of cultural settings.

This comparison produced a list of 32 items which were either identical or very similar in meaning. From these, 20 items were selected by agreement between the chief investigators in the first-phase study area teams on the basis of ease of translation and cultural relevance. The 4 additional items, designed to detect psychotic conditions, were based on the items in Foulds' Symptom Sign Inventory (Foulds \& Hope, 1968) which have been shown to be most effective in detecting psychotic illness.

Since most attending patients were illiterate, the SRQ items were read to the patient by a research assistant. In most instances the research assistants were selected from among local people. They underwent a 5-hour training in the administration of the questionnaire. This included the recording of responses of several patients to whom the questions were read by a trained investigator until such responses were reliably recorded.

The English version of the 20 'non-psychotic' items and the 4 'psychotic' items of the SRQ is shown in the Appendix.

\section{Follow-up}

On the basis of pilot testing, a cut-off point for the total score on the 20 'non-psychotic' items of the SRQ was selected for each study area. This selection was based on the score which was likely to yield optimal sensitivity and specificity, i.e. to yield as few false positives and false negatives as possible. ${ }^{1}$ All patients scoring above this cut-off point or scoring at least one positive item on the 4 'psychotic' items were regarded as 'potential cases' and followed up. In addition, a sample of those cases scoring less than the 'non-psychotic' cut-off point and with no positive 'psychotic' items were also followed up.

The follow-up procedure included:

(i) A structured psychiatric interview: the shortened version of the Present State Examination (PSE). The PSE was administered by research psychiatrists who had undergone a recognized training in the use of the PSE in English and had been given further experience in its use in local languages.

(ii) A diagnostic assessment and formulation (DAF) completed on the basis of the PSE ratings. Once again, research psychiatrists made these diagnoses and inter-centre reliability has been checked (WHO, in preparation).

(iii) A confidential case register established for each study area in which details of those patients identified as psychiatric cases were entered.

The screening procedure is summarized in Fig. 1.

\section{Translation and training}

All instruments were translated by study teams into local languages as necessary and appropriate, e.g. in RR, SJA and SAM research workers

1 The details of the item selectron, calibration and testing of validity are not given in this paper as they are being published separately in a monograph describing all methods developed in the course of the collaborative study (WHO, in preparation). Nevertheless, it is of interest to note that the cut-off points selected after calibration of the instrument in the different study areas varied as follows: UVP, 10/11; RR, 5/6; SJA, 3/4; SAM, 6/7. 


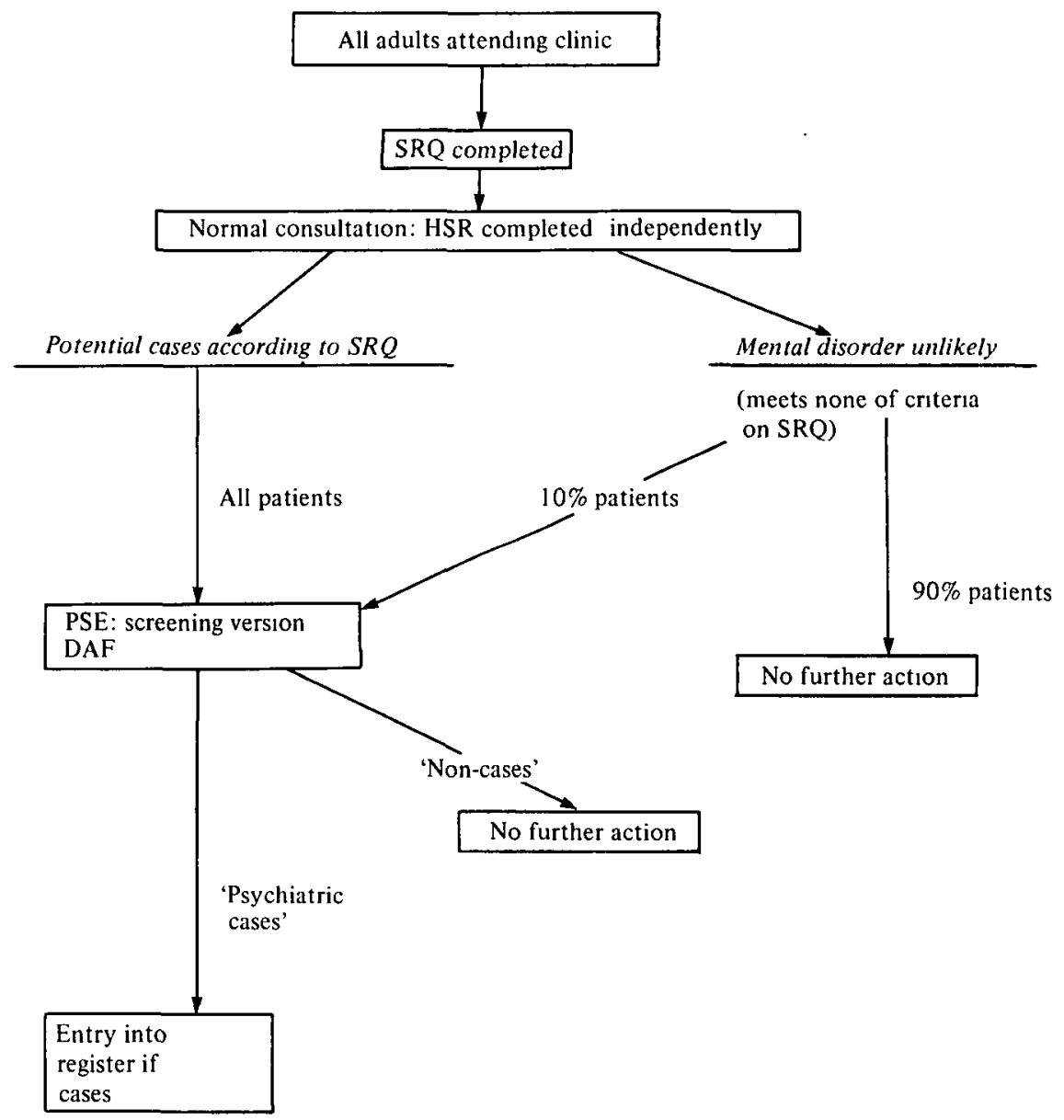

FIG. 1. Case detection procedure: diagrammatic representation. SRQ, Self Reporting Questionnaire; HSR, Health Staff Rating; PSE, Present State Examination (screening version); DAF, Diagnostic Assessment Form.

could use English but all questions put to patients had to be translated into Hindi, Arabic and Filipino. Back translations were made independently by workers who did not know the original version. Where necessary, adjustments were then made to the original translation. Research workers were trained in groups, starting by administering the screening schedules to each other and proceeding to practising with 20 patients before the screening proper was started.

\section{RESULTS}

\section{The validity of the screening process}

The results of this study depend on the reliability and validity of the two-stage process used to detect psychiatric morbidity. The performance of the 24-item screening instrument has been assessed by administering the questionnaire to a group of normal subjects from each of the study areas and calculating the sensitivity and specificity of the instrument at the cut-off point selected for each study area. The sensitivity varied between $73 \%$ and $83 \%$ in the 4 study areas, while the specificity varied between $72 \%$ and $85 \%$. These figures mean that the overall misclassification rate in a population with a psychiatric morbidity rate of $15 \%$ would vary between $18 \%$ and $24 \%$. The second stage of the detection process was based on a Present State Examination interview, a method which has been widely used and reviewed in many 
countries. A reliability exercise was carried out between the psychiatrists making diagnostic ratings. This showed a high level of agreement in discriminating between 'cases' and 'noncases', but lower levels of agreement on specific diagnostic entities at the fourth digit level of ICD-8 (e.g. between 'depressive' and 'anxiety' neuroses). Full details concerning the validity and reliability of the methods used are given in a section of a monograph describing all the new methods developed and tested in the course of the collaborative study (WHO, in preparation).

\section{The populations screened}

The numbers screened in each area were 444 in UVP, 361 in RR, 360 in SJA and 459 in SAM, making a total of 1624 . No patients refused to be screened; 5 patients in UVP, 6 in RR and 4 in SJA could not be screened because their conditions needed urgent attention. The male: female ratios were $1: 6.9$ in UVP, $1: 2.0$ in $R R$, $1: 1.8$ in SJA and $1: 3.5$ in SAM. The preponderance of women in UVP and SAM reflects the emphasis given to maternal care (antenatal, natal and postnatal) in the health services of these areas.

\section{The frequency of mental disorders}

The diagnostic assessment and formulation allowed for 3 possible categories: 'non-cases', 'possible cases' and 'definite cases'. In establishing frequency of mental disorders, we have considered only 'definite cases'. The frequency has been established in the following way. The denominator was simply the total number of individuals screened. The ordinator was the sum of (i) all 'potential cases' (by SRQ) identified as 'definite cases' in the follow-up; and (ii) an estimate of the number of cases missed by the first-stage screening, based on the frequency of 'definite cases' among the sample of patients who did not otherwise meet the criteria for follow-up. This estimate was the minimum number of definite cases in the group from which this sample was drawn at the $95 \%$ level of probability. Thus $t w o$ decisions were made, representing a conservative approach to the estimate of frequency on the basis of our data. It is therefore reasonable to regard the figures obtained as indicating minimum estimates of the level of mental morbidity. The detailed results are shown in Table 1. The estimate of frequency of
Table 1. Frequency of mental disorder among adults attending primary health care facilities as estimated by a two-stage screening process

\begin{tabular}{|c|c|c|c|c|c|}
\hline \multirow[b]{2}{*}{. } & \multicolumn{5}{|c|}{ Study areas } \\
\hline & UVP & RR & SJA & SAM & $\begin{array}{l}\text { Com- } \\
\text { bined } \\
\text { results }\end{array}$ \\
\hline Patients screened (cases) & 444 & 361 & 360 & 459 & 1624 \\
\hline $\begin{array}{l}\text { 'Potential' cases identi- } \\
\text { fied as 'definite cases' } \\
\text { on follow-up" }\end{array}$ & 46 & 61 & 37 & 66 & 210 \\
\hline $\begin{array}{l}\text { Estimate of additional } \\
\text { cases missed by first- } \\
\text { stage screen } \dagger\end{array}$ & 2 & 3 & 1 & 9 & 15 \\
\hline $\begin{array}{l}\text { Minimum estimate of } \\
\text { cases }(\%)\end{array}$ & $\begin{array}{c}48 \\
(10 \cdot 8)\end{array}$ & $\begin{array}{c}64 \\
(17 \cdot 7)\end{array}$ & $\begin{array}{c}38 \\
(10 \cdot 6)\end{array}$ & $\begin{array}{c}75 \\
(16 \cdot 3)\end{array}$ & $\begin{array}{l}225 \\
(13 \cdot 9)\end{array}$ \\
\hline
\end{tabular}

* 'Potential cases' identified as 'possible cases' on followup are excluded from consideration.

$\dagger$ Based on sample of patients who passed first-stage screen not identified as possible cases, calculated as minimum number at $95 \%$ level of probability.

Table 2. Diagnoses of mental disorders (\%) seen in primary health care

\begin{tabular}{lc}
\hline \multicolumn{1}{c}{ Diagnosis* } & $\begin{array}{c}\text { All mental } \\
\text { disorders } \\
(N=288)\end{array}$ \\
\hline Depressive neurosis (300.4) & $48 \cdot 6$ \\
Anxiety neurosis (300.0) & $30 \cdot 9$ \\
Other neurosis (other 300) & $8 \cdot 3$ \\
Schizophrenia (295) & $3 \cdot 1$ \\
Mental retardation (310/311/312) & $2 \cdot 1$ \\
Affective psychosis (296) & $1 \cdot 7$ \\
Others (-) & $5 \cdot 2$ \\
\hline \hline
\end{tabular}

* The corresponding codes from 1CD-8 are given in parentheses.

mental disorders in the 4 areas is $10.8 \%$ in UVP, $17.7 \%$ in RR, $10.6 \%$ in SJA and $16.3 \%$ in SAM. The combined 'minimum' frequency based on 1624 adult attenders in primary health care facilities in 4 countries is $13.9 \%$.

The great majority of these cases were diagnosed as being neurotic disorders, as is shown in Table 2 (which is, however, based on both 'definite' and 'possible' cases). Few cases of functional psychosis or mental retardation were diagnosed.

\section{Diagnostic ratings by health staff and their accuracy}

Most patients were diagnosed as having physical health problems, as shown in Table 3. In UVP 
Table 3. Diagnostic ratings by health staff $(\%)$

\begin{tabular}{|c|c|c|c|c|}
\hline & $\begin{array}{c}\text { UVP } \\
(N=444)(N\end{array}$ & $\begin{array}{l}\text { RR } \\
N=361)(N\end{array}$ & $\begin{array}{l}\text { SJA } \\
I=360)(\end{array}$ & $\begin{array}{c}\text { SAM } \\
N=459)\end{array}$ \\
\hline $\begin{array}{l}\text { Physical health } \\
\text { problem }\end{array}$ & $85 \cdot 6$ & $86 \cdot 1$ & $95 \cdot 8$ & $71 \cdot 5$ \\
\hline $\begin{array}{l}\text { Mental health } \\
\text { problem }\end{array}$ & $1 \cdot 8$ & $4 \cdot 4$ & $2 \cdot 5$ & 0.9 \\
\hline $\begin{array}{l}\text { Physical and } \\
\text { mental health } \\
\text { problem }\end{array}$ & $7 \cdot 7$ & $8 \cdot 3$ & $1 \cdot 4$ & $21 \cdot 1$ \\
\hline No health problem & $3 \cdot 2$ & $1 \cdot 1$ & - & $6 \cdot 5$ \\
\hline Unable to rate & $1 \cdot 8$ & 一 & 0.3 & - \\
\hline
\end{tabular}

and $\mathrm{RR}$ the health workers were ready to make a diagnosis of physical and mental health problems in $7-8 \%$ of patients, while in SJA such combined diagnoses were much less frequent. In SAM there was a strikingly higher rate of such diagnoses $(21 \cdot 1 \%)$. The overall frequency with which health staff diagnosed mental health problems (either alone or in combination with physical disorders) was $9.5 \%$ in UVP, $12.7 \%$ in RR, $3.9 \%$ in SJA and $22 \%$ in SAM. These frequencies are lower than the frequency of mental disorder found by the screening procedure in UVP, RR and SJA, but the difference is greater in SJA than the other areas. In SAM, on the other hand, the health staff diagnosed more cases of mental disorder than were detected by the two-stage screening procedure.

It is not, however, only the rate of diagnoses which indicates the diagnostic skill of the health worker, since both false positive and false negative diagnoses may be made. Table 4 shows the relationship between diagnoses by health workers and the cases detected by the two-stage screening procedure, with a decision by a psychiatrist as final criterion of 'caseness'. In this and subsequent tables, both 'definite' and 'possible' cases are included, since we are no longer considering frequency as such, when it was reasonable to take a cautious approach. The issue is now diagnostic skill, so that we would hope that health workers would be able to detect both 'definite' and 'possible' cases. From Table 4 it can be seen that, of the 288 cases detected by the screening procedure, roughly one third were diagnosed by health workers and two thirds were missed. Based on this table, the diagnostic sensitivity (a measure of how few cases are missed) and specificity (a measure of how few non-cases are diagnosed) can be cal-
Table 4. Comparison between health staff diagnoses and case detection by screening procedure in 1624 consecutive adult attenders at primary health care facilities in all 4 areas

\begin{tabular}{|c|c|c|c|}
\hline \multirow[b]{2}{*}{$\begin{array}{l}\text { Detection } \\
\text { by screening } \\
\text { procedure }\end{array}$} & \multicolumn{2}{|c|}{ Diagnosis by health staff } & \multirow[b]{2}{*}{ Total } \\
\hline & $\begin{array}{l}\text { 'Mental } \\
\text { disorder } \\
\text { present' }\end{array}$ & $\begin{array}{l}\text { 'Mental } \\
\text { disorder not } \\
\text { present' }\end{array}$ & \\
\hline $\begin{array}{l}\text { Cases } \\
\text { Non-cases }\end{array}$ & $\begin{array}{r}106 \\
97\end{array}$ & $\begin{array}{r}182 \\
1239\end{array}$ & $\begin{array}{r}288 \\
1336\end{array}$ \\
\hline Total & 203 & 1421 & 1624 \\
\hline
\end{tabular}

Frequency of mental disorder by two-stage screening procedure $=17.7 \%$. (This frequency is higher than that quoted earlier in section 3 , since it includes 'possible cases' as well as 'definite cases'.)

Rate of diagnosis of mental disorder by existing health staff $=6.5 \%$, their diagnostic sensitivity $=36.8 \%$, their diagnostic specificity $=92.7 \%$.

culated. The diagnostic sensitivity is relatively low $(36.8 \%)$, while the diagnostic specificity is high $(92.7 \%)$; i.e. for every 3 cases of mental disorder coming to primary health care, 1 will be diagnosed as such by the health worker; while for every 100 non-cases, only between 7 and 8 will be wrongly diagnosed as suffering from mental disorder. The findings on so-called 'false positive' diagnoses need qualification, since it is entirely possible that the health workers were in certain cases more sensitive to mental disorders than the research procedure (Giel \& Le Nobel, 1971). The significant finding is that this variety of discordance (psychiatric case identified by the health worker but not by the research procedure) occurred only half as frequently as the other variety of discordance (psychiatric case identified by the research procedure but not by the health worker). The combined figures mask important differences between SAM and the 3 other study areas. The diagnostic sensitivity in SAM was $46.9 \%$ and the diagnostic specificity $83.3 \%$. Thus, in SAM, nearly half the cases were being correctly diagnosed, while in the other 3 study areas less than one third were diagnosed by the health workers.

\section{Reasons for attendance}

The many reasons for attendance quoted by attenders could all be classified as 1 of 90 items listed under 9 headings: (a) generalized symptoms (e.g. fever, weakness); (b) pains, discomforts and 
Table 5. Number of reasons for attendance quoted by patients in 4 study areas

\begin{tabular}{|c|c|c|c|c|c|c|c|c|c|c|}
\hline \multirow{2}{*}{$\begin{array}{l}\text { Number of } \\
\text { reasons }\end{array}$} & \multicolumn{2}{|c|}{ UVP } & \multicolumn{2}{|c|}{$\mathbf{R R}$} & \multicolumn{2}{|c|}{ SJA } & \multicolumn{2}{|c|}{ SAM } & \multicolumn{2}{|c|}{ All 4 areas } \\
\hline & No. & $\%$ & No. & $\%$ & No. & $\%$ & No. & $\%$ & No. & $\%$ \\
\hline $\begin{array}{c}1 \\
2 \\
3 \text { or more }\end{array}$ & $\begin{array}{r}379 \\
45 \\
20\end{array}$ & $\begin{array}{r}85 \cdot 4 \\
10 \cdot 1 \\
4 \cdot 5\end{array}$ & $\begin{array}{r}267 \\
59 \\
35\end{array}$ & $\begin{array}{r}74 \cdot 0 \\
16 \cdot 3 \\
9 \cdot 7\end{array}$ & $\begin{array}{r}206 \\
106 \\
48\end{array}$ & $\begin{array}{l}57 \cdot 2 \\
29 \cdot 4 \\
13 \cdot 3\end{array}$ & $\begin{array}{r}370 \\
69 \\
20\end{array}$ & $\begin{array}{r}80 \cdot 6 \\
15 \cdot 0 \\
4 \cdot 4\end{array}$ & $\begin{array}{r}1222 \\
279 \\
123\end{array}$ & $\begin{array}{r}75 \cdot 2 \\
17 \cdot 2 \\
7 \cdot 6\end{array}$ \\
\hline Total & 444 & & 361 & & 360 & & 459 & & 1624 & \\
\hline
\end{tabular}

Table 6. Relationship between the number of reasons quoted, the diagnosis of mental disorder by health staff, and the detection of mental disorder by two-stage screening including a psychiatric interview

\begin{tabular}{lcc}
\hline \hline & $\begin{array}{c}\text { Cases (\%) of mental disorder } \\
\text { diagnosed by }\end{array}$ \\
Number of reasons & $\begin{array}{c}\text { Regular health } \\
\text { staff }\end{array}$ & $\begin{array}{c}(b) \text { Two-stage } \\
\text { screening } \\
\text { procedure }\end{array}$ \\
\hline $1(N=1222)$ & 12.1 & 15.9 \\
$2(N=279)$ & 12.9 & 20.1 \\
3 or more $(N=123)$ & 15.4 & 30.1 \\
\hline \hline
\end{tabular}

irritations; $(c)$ respiratory symptoms; $(d)$ gastrointestinal symptoms; $(e)$ genito-urinary symptoms; $(f)$ psychological, neurological and sensory symptoms; $(g)$ other symptoms; $(h)$ 'diagnoses'; (i) other reasons. Most patients quoted one symptom as reason for attendance, as shown in Table 5 , but a minority gave 2 or more reasons (this minority being more substantial in SJA than in the other areas). A few patients quoted not a symptom but a diagnosis as reason for attendance - e.g. hypertension, malaria, worms, asthma - while some patients attended for various forms of routine care (e.g. family planning, antenatal care). Table 6 , which pools results from the 4 areas, shows that those patients quoting 3 or more reasons for attendance have twice the chance of suffering from mental disorder (nearly 1 in 3 as opposed to 1 in 6). The pattern of health workers' diagnostic ratings shows little variation with number of reasons for attendance quoted by patients.

All reasons for attendance quoted by at least $1 \%$ of patients are listed in Table 7 . The five commonest reasons were headache, abdominal pain, cough, genito-urinary symptoms and fever. At least one of these reasons was quoted by over half the patients. Psychological symptoms, such as anxiety, depression and sleep disturbance, were quoted infrequently as reasons for attendance. Table 7 shows that the proportion of mental disorders among patients quoting 1 of the 12 most common reasons varies from $6.8 \%$ in the case of women attending for antenatal or postnatal care to $35.5 \%$ and $28.9 \%$ among those quoting 'weakness' and 'dizziness' respectively. Health staff show, in fact, a low rate of diagnosis of mental disorders among women attending for antenatal or postnatal care, but their rate is also low (and markedly discrepant with the rate found in the screening procedure) in the case of cough, fever and back pain. Most patients presenting with mental disorders, therefore, gave a physical symptom as reason for attendance. The majority of such cases missed by the health workers were among patients complaining of headache, abdominal pain, cough, back pain and weakness.

\section{CONCLUSIONS}

Mental disorders do make up a significant proportion of morbidity seen in primary health care in the 4 communities studied. The frequency recorded, using a carefully standardized twostage screening procedure, was between $10.6 \%$ and $17.7 \%$, a little lower than has been found in industrialized countries (Kessel \& Shepherd, 1962; Shepherd et al. 1966; Goldberg \& Blackwell, 1970; Dilling et al. 1978). We have, however, deliberately taken a conservative approach in reaching these estimates, to pre-empt any criticism that the rates are inflated or do not represent 'true psychiatric morbidity'. Our finding that there is indeed a significant rate of psychiatric morbidity in the primary health care setting of developing countries is more important than the finding that this rate is somewhat lower than has been reported from industrialized countries. 
Table 7. Twelve commonest reasons for attendance ranked in order of frequency as related to diagnosis of mental disorder by health staff and detection of mental disorder by screening procedure

\begin{tabular}{|c|c|c|c|}
\hline Reason for attendance & $\begin{array}{l}\text { Number of patients } \\
\text { quoting reason } \\
(N=1624)\end{array}$ & $\begin{array}{c}\text { Patients }(\%) \text {, quoting } \\
\text { reason, diagnosed } \\
\text { by health staff as } \\
\text { suffering from } \\
\text { mental disorder }\end{array}$ & $\begin{array}{l}\text { Patients }(\%) \text {, quoting } \\
\text { reason, } \\
\text { detected by screening } \\
\text { procedure as having } \\
\text { psychiatric disorder }\end{array}$ \\
\hline 1. Headache & 208 & $14 \cdot 4$ & $23 \cdot 0$ \\
\hline 2. Abdominal pain & 170 & $12 \cdot 4$ & 21.8 \\
\hline 3. Cough & 167 & $13 \cdot 2$ & $18 \cdot 0$ \\
\hline 4. Genito-urinary & 129 & $15 \cdot 5$ & $16 \cdot 3$ \\
\hline 5. Fever & 128 & $8 \cdot 6$ & $13 \cdot 3$ \\
\hline 6. Dizziness & 90 & 28.9 & $28 \cdot 9$ \\
\hline 7. Antenatal/postnatal care & 88 & $3 \cdot 4$ & $6 \cdot 8$ \\
\hline 8. Back pain & 79 & $11 \cdot 4$ & $28 \cdot 6$ \\
\hline 9. Chest pain & 78 & $17 \cdot 9$ & $21 \cdot 8$ \\
\hline 10. Weakness & 76 & $22 \cdot 4$ & $35 \cdot 5$ \\
\hline 11. Cold/influenza & 67 & 11.9 & $17 \cdot 9$ \\
\hline 12. Family planning & 54 & $11 \cdot 1$ & $24 \cdot 1$ \\
\hline
\end{tabular}

The disorders detected were mainly neuroses, as has been found in earlier studies at primary care level in industrialized countries (Pemberton, 1949; Kessel, 1960; Shepherd et al. 1966) and by Ndetei \& Muhangi (1979) in Kenya. This finding raises some awkward questions. One of the basic tenets in the provision of mental health care in developing countries is the need to select priorities according to clearly established criteria (WHO, 1975; Giel \& Harding, 1976). In following this principle, the teams participating in this study have already established priorities for interventions (Harding, 1978; Harding et al. 1979) in which psychotic conditions, presenting as acute emergencies or as chronic disablement, figure prominently. The teams have also identified the primary health worker as the main agent for assuring simple mental health care (WHO, 1979). Yet our finding is that neurotic conditions are commonly encountered by primary health workers in their everyday work, while psychotic disorders are rare. Indeed, so few psychotic patients were detected in the screening exercise that it is not possible to draw conclusions about the health workers' ability to diagnose such patients. The disinclination of psychotic patients to seek help at primary health facilities is clearly related to the attitudes and perceptions of mental illness which we have studied in a community survey, reported elsewhere (Wig et al. 1980). Reaching psychotic patients who do not present spontaneously at primary health care facilities calls for active case finding by primary health workers in the community. Meanwhile, such workers also need an effective means of coping with the large numbers of patients with neurotic conditions who seek help of their own accord.

In coping with patients with neurotic complaints, one aim will be to avoid inappropriate investigations, referral and treatment and to prevent the build up of a cycle of frequent attendance and 'medicalization' of underlying social problems. Although we have not presented data in this paper on attendance rates, it is our impression that patients with neurotic conditions presenting with somatic symptoms tend to consult primary care facilities on successive occasions, to seek help elsewhere and to be given inappropriate, symptomatic drug treatment. We are collecting more systematic data to test this impression but the phenomenon has been well described elsewhere, for example by Giel \& Workneh (1980) in Ethiopia and by Holmes \& Speight (1975) in Tanzania. Many neurotic conditions are likely to be self limiting, providing that maladaptive, coping mechanisms are not established during the early stages of the illness. The health worker should be able to tell patients confidently when no disorder requiring medical intervention is found and to encourage patients to seek help within the community for underlying social problems. This means building up a close relationship with community leaders, traditional healers, religious leaders, teachers and other influential people who can help those with social problems. The same contacts will be useful for finding patients 
with psychotic illnesses, many of whom are kept out of public view by their families. The health worker needs to establish confidence in the community that such patients can be helped by a combination of active medical and social management.

Our results show that, with their present level of training, health staff in the study areas diagnose only one third of the cases of mental disorder among the patients they see. The tendency of health workers to miss cases of mental disorder has often been noted previously. Kessel \& Shepherd (1962) have pointed out the complexity of the task of detecting psychological disturbance in a setting of general morbidity. Goldberg \& Blackwell (1970) found that even a general practitioner who was also a psychiatrist 'failed to detect one third of the disturbed patients' detected by a research procedure. Giel \& Le Nobel (1971), in their studies of a Dutch general practice, found that the practitioners considered as 'likely psychiatric cases' only one half of the 'certain or probable cases' identified by two research psychiatrists. Studies of general practice in Bavaria (Dilling et al. 1978) have also shown that a considerable proportion of psychiatric cases are missed. In a general hospital study, physicians were found to miss about two thirds of all psychiatric cases among new outpatients (Mezey \& Syed, 1975). Missing psychiatric cases at primary care level is a world wide phenomenon and the need for greater awareness of psychological disturbance and for improved diagnostic skills is a general one. Our results are therefore in no way an indictment of primary health workers in developing countries.

The rate of diagnosis of mental disorders by the health workers in patients who were not detected in the research procedure was low, but nevertheless accounted for $97(6.0 \%)$ patients in our total sample of 1624 . Giel \& Le Nobel (1971) found $8.0 \%$ of patients falling into this category, while Goldberg \& Blackwell's (1970) figures suggest a much lower rate of about $1 \%$. These patients may represent 'false positive' diagnoses by the health worker or, alternatively, cases missed by the research procedure and correctly diagnosed by the health worker. Whichever interpretation is more correct, our data suggest that, at the present time, the tendency to miss cases is operationally more important than any risk of overinclusive diagnosis.
The tendency to miss psychiatric cases is probably linked to another finding in the study: the majority of patients with mental disorder complain primarily of physical symptoms. Some of these symptoms are those that are usually regarded as potentially 'psychosomatic': headache, dizziness and weakness. There is also a strong association between polysymptomatic presentation and mental disorder, as would be expected. What is more surprising is the rate of mental disorder among patients complaining of cough and fever and among women coming for family planning advice, all of whom have a rate in excess of $13 \%$. It seems that many patients assume that a physical symptom is almost a requirement in order to be seen at a health facility. In British general practice, Kessel (1962) has estimated that only $10 \%$ of psychiatric patients present with psychological symptoms. Our own experience shows that the presenting complaint, once presented, often becomes insignificant. Many patients, for example, who complained of fever were found to have a normal body temperature. Few patients offered their 'psychiatric' symptoms as presenting complaints, although these were often present on enquiry. In India, for example, people would rarely think of a doctor as somebody to whom one would talk about one's feelings. Only when a patient's mental status impinged on his physical sensations would he seek medical advice.

The results reported in this paper have led us to two main conclusions.

(1) Primary health workers in developing countries do see mental disorders regularly among their patients. They recognize only a minority. It will be important to improve their diagnostic skills so that they may recognize the patients with mental disorders and provide appropriate management.

(2) Improved diagnosis will not, however, be sufficient to reach those patients with severe mental disorders, such as schizophrenia or depressive psychosis, who do not normally present themselves at primary health facilities. Contact with the community will also be needed to change attitudes and to demonstrate that such people can be helped.

Each team participating in the study has drawn up a comprehensive strategy of interventions, including the training of primary health workers, a system of referral and super- 
vision, the supply of drugs, and community participation (Harding, 1978; WHO, 1979). The strategy is based on a number of basic principles put forward by a WHO Expert Committee (WHO, 1975). It has also been strongly influenced by the results reported here and by other observations made in the same study areas (Wig et al. 1980; Giel et al. in preparation).

Interventions have now been introduced in the study areas and we have already drawn preliminary conclusions concerning the feasibility of including mental health care at primary level in developing countries (Harding et al. 1979). The final phase of our collaborative work will consist of a detailed and objective evaluation of these interventions.

The authors express their warm thanks to the very many people in different countries who have con-

\section{APPENDIX}

\section{Items of the Self Reporting Questionnaire (SRQ)}

'Non-psychotic'

1. Do you often have headaches?

2. Is your appetite poor?

3. Do you sleep badly?

4. Are you easily frightened?

5. Do your hands shake?

6. Do you feel nervous, tense or worried?

7. Is your digestion poor?

8. Do you have trouble thinking clearly?

9. Do you feel unhappy?

10. Do you cry more than usual?

11. Do you find it difficult to enjoy your daily activities?

12. Do you find it difficult to make decisions?

13. Is your daily work suffering?

14. Are you unable to play a useful part in life?

15. Have you lost interest in things?

16. Do you feel that you are a worthless person?

17. Has the thought of ending your life been in your mind?

18. Do you feel tired all the time?

19. Do you have uncomfortable feelings in your stomach?

20. Are you easily tired?

\section{'Psychotic'}

1. Do you feel that somebody has been trying to harm you in some way?

2. Are you a much more important person than most people think?

3. Have you noticed any interference or anything else unusual with your thinking?

4. Do you ever hear voices without knowing where they come from or which other people cannot hear? 


\section{REFERENCES}

Climent, C. E. \& Plutchick, R. (1980). Confiabilidad, validez y sensibilidad de los ítemes de una escala de auto-reportaje de sintomas de enfermedad mental. Revista Colombiana de Psiquiatria (in the press).

Dilling, H., Weyerer, S. \& Enders, I. (1978). Patienten mit psychischen Störungen in der Allgemeinpraxis und ihre psychiatrische Überweisungsbedürftigkeit. Monographien aus dem Gesamtgebiete der Psychiatrie (Berlin) 17, 135160.

Foulds, G. A. \& Hope, K. (1968). Manual of the Symptom Sign Inventory $(S S I)$. University of London Press: London.

Giel, R. \& Harding, T. W. (1976). Psychiatric priorities in developing countries. British Journal of Psychiatry 128, 513-522.

Giel, R. \& Van Luijk, V. N. (1969). Psychiatric morbidity in a small Ethiopian town. British Journal of Psychiatry 115 , 149-162.

Giel, R. \& Le Nobel, C. P. J. (1971). Neurotic instability in a Dutch village. Acta psychiatrica scandinavica 47, 462472.

Giel, R. \& Workneh, F. (1980). Coping with outpatients who cannot cope - management of persistent complainers in an African country. Transactions of the Royal Society of Tropical Medicine and Hygiene (in the press).

Giel, R., de Arango, M. V., Climent, C. E., Harding, T. W., Ibrahim, H. H. A., Ladrido-Ignacio, L., Srinivasa Murthy, R., Salazar, M. C. I., Wig, N. N. \& Younis, Y. O. A. (in preparation). Childhood mental disorders in primary health care.

Goldberg, D. P. (1972). The Detection of Psychiatric Illness by Questionnaire. Oxford University Press: London.

Goldberg, D. P. (1974). Psychiatric disorders (a series on 'screening for disease'). Lancet ii, 1245-1247.

Goldberg, D. P. \& Blackwell, B. (1970). Psychiatric illness in general practice. A detailed study using a new method of case identification. British Medical Journal ii, 439-443.

Harding, T. W. (1973). The detection of psychiatric illness by questionnaire in Jamaica. West Indian Medical Journal 22, 190-191.

Harding, T. W. (1976). Validating a method of psychiatric case identification in Jamaica. Bulletin of the World Health Organization 54, 225-231.

Harding, T. W. (1978). Psychiatry in rural agrarian societies. Psychiatric Annals 8, 74-84.

Harding, T. W., Climent, C. E., Collignon, R., Diop, B.S. M., Giel, R., Guèye, M., Ibrahim, H. H. A., Ladrido-Ignacio, L. \& Wig, N. N. (1979). Santé mentale et soins de santé primaires: premiers résultats d'une étude concertée de l'OMS. Psychopathologie africaine 15 (1), 5-28.
Holmes, J. A. \& Speight, A. N. P. (1975). The problem of non-organic illness in Tanzanian urban medical practice. East African Medical Journal 52, 225-236.

Kessel, W. I. N. (1960). Psychiatric morbidity in a London general practice. British Journal of Preventive and Social Medicine 14, 16-22.

Kessel, W. I. N. (1962). Conducting a psychiatric survey in general practice. In The Burden on the Community (ed. J. D. N. Hill), pp. 13-30. Nuffield Provincial Hospitals Trust: London.

Kessel, N. \& Shepherd, M. (1962). Neurosis in hospital and general practice. Journal of Mental Science 108, 159-165.

Mbanefo, S. E. (1971). The general practitioner and psychiatry. In Psychiatry and Mental Health Care in General Practice (ed. A. Boroffka), pp. 45-49. University of Ibadan: Ibadan.

McEvoy, P. J. \& McEvoy, H. F. (1976). Management of psychiatric problems in a Kenyan mission hospital. British Medical Journal i, 1454-1456.

Mezey, A. G. \& Syed, I. A. (1975). Psychiatric illness and attitudes to psychiatry. Social Psychiatry 10, 133-138.

Ndetei, D. M. \& Muhangi, J. (1979). The prevalence and clinical presentation of psychiatric illness in a rural setting in Kenya. British Journal of Psychiatry 135, 269-272.

Pemberton, J. (1949). Illness in general practice. British Medical Journal i, 306-308.

Shepherd, M., Cooper, B., Brown, A. C. \& Kalton, G. (1966). Psychiatric Illness in General Practice. Oxford University Press: London.

Verma, S. K. \& Wig, N. N. (1977). Standardisation of a neuroticism questionnaire in Hindi. Indian Journal of Psychiatry 19, 67-72.

Wig, N. N., Suleiman, M. A., Routledge, R., Srinivasa Murthy, R., Ladrido-Ignacio, L., Ibrahim, H. H. A. \& Harding, T. W. (1980). Community reactions to mental disorders: a key informant study in three developing countries. Acta psychiatrica scandinavica 61, 111-126

Wing, J. K., Cooper, J. E. \& Sartorius, N. (1974). The Measurement and Classification of Psychiatric Symptoms. Cambridge University Press: Cambridge.

World Health Organization (1975). Organization of Mental Health Services in Developing Countries. Sixteenth Report of the WHO Expert Committee on Mental Health. Technical Report Series No. 564. WHO: Geneva.

World Health Organization Regional Office for Africa (1979). Mental Health: Report of the WHO Regional Expert Panel on Mental Health. AFRO Technical Report Series No. 7. Brazzaville.

World Health Organization (in preparation). Provisional title: Community Mental Health in Developing Countries. 